ONDE ERROU SUN TZU: ESTUPRO COMO ESTRATÉGIA MILITAR, A ATUAÇÃO DO TRIBUNAL PENAL INTERNACIONAL E O POSICIONAMENTO DOS ESTADOS SOBERANOS À LUZ DO JUS

\title{
IN BELLO
}

\section{LUIZA BATISTA BELÉM}

Graduanda em Direito, modalidade integral, pela Escola Superior Dom Helder Câmara. Belo Horizonte. E-mail: luizabelemb@gmail.com

CAIO AUGUSTO SOUZA LARA Mestre e Doutor em Direito pela Faculdade de Direito da Universidade Federal de Minas Gerais - UFMG. Professor da Escola Superior Dom Helder Câmara. Pesquisador Associado ao Programa RECAJ-UFMG - Acesso à Justiça e Solução de Conflitos. Secretário de Comunicação do Conselho Nacional de Pesquisa e Pósgraduação em Direito - CONPEDI. Belo Horizonte-MG. E-mail: caiolarabh@yahoo.com.br.

\section{RESUMO}

O tema-problema da presente pesquisa que se pretende desenvolver é a análise dos desafios relacionados à punição do estupro como crime de guerra e estratégia militar no Tribunal Penal Internacional à luz do Direito Humanitário. Sob esse prisma, reputa-se fundamental uma análise tanto da conjuntura sociológica no que se refere à sociedade global quanto do ordenamento jurídico internacional. A importância de se discutir o tema se pauta no paradoxo da necessidade de proteção da pessoa humana na conjuntura da guerra, garantida por norma de caráter peremptório, versus a omissão dos órgãos e sujeitos de Direito Internacional frente à punição e prevenção do crime de estupro como estratégia militar em conflitos internos 


\section{Personalidade Acadêmica Homenageada:}

Raymundo Juliano Feitosa (Universidade Federal do Rio Grande do Norte - UFRN)

e externos. Nessa conjuntura, o estupro como estratégia militar, que foi amplamente utilizado durante a $2^{\mathrm{a}}$ Guerra Mundial, continua sendo uma estratégia recorrente como forma de desestabilizar a comunidade e alterar a composição étnica de determinado grupo. O que se nota, portanto, é que por mais que a proteção das mulheres civis seja respaldada pelo Direito Humanitário, a efetivação de políticas de prevenção e punição dos responsáveis pelo tipo de violência aqui tratado tem sido colocada em dúvida, vez que a positivação da norma não resultou em uma melhora no quadro das mulheres (civis e combatentes) em conflitos armados até então. Resta, portanto, analisar o papel do Tribunal Penal Internacional que, em tese, desde sua instituição há quase duas décadas, teria jurisdição para julgar autoridades governamentais responsáveis por estupro como estratégia militar. Logo, o problema objeto da investigação científica proposta é: quais são os principais desafios que dificultam a punição do estupro como crime de guerra e estratégia militar no Tribunal Penal Internacional à luz do Direito Humanitário? A partir das reflexões preliminares sobre o tema, é possível afirmar inicialmente que fatores como o debate entre jurisdições nacional e internacional, bem como o número relativamente baixo de estados parte do Tribunal Penal Internacional pelo Estatuto de Roma são desafios claros à efetivação da punição de crime de estupro como estratégia militar pelo Tribunal. Sob esse prisma, por mais que a norma que proíbe o estupro como uma estratégia militar sejam rígidas, a sua aplicação vai de encontro a interesses exclusos de autoridades nacionais e ao excesso de positivação do Direito Internacional. Nesse diapasão, o objetivo geral do trabalho é analisar de maneira aprofundada os desafios que permeiam a punição dos responsáveis por utilizarem o estupro como estratégia militar nos conflitos hodiernos. $O$ presente projeto se enquadra predominantemente na vertente metodológica jurídico-dogmática e se baseia na investigação jurídico-diagnóstica de caráter dialético. De acordo com a técnica de análise de conteúdo, afirma-se que se trata de uma pesquisa teórica, o que será possível a partir da análise de conteúdo dos textos doutrinários, normas e demais dados colhidos na pesquisa, vez que, por mais importante que seja a análise sociológica acerca do tema, para fins de cumprimento do objetivo geral do trabalho, é preciso dar ênfase às questões dogmáticas relacionadas. Por fim, conclui-se que o índice relativamente baixo de Estados que 
Personalidade Acadêmica Homenageada:

Raymundo Juliano Feitosa (Universidade Federal do Rio Grande do Norte - UFRN)

aceitam a jurisdição do Tribunal Penal Internacional e a falta de jurisprudência no que se refere ao julgamento desse crime constitui um enorme desafio à garantia dos Direitos das Mulheres e mostra a necessidade de novos estudos doutrinários acerca do tema, bem como a sensibilização dos governantes para a mudança de postura com relação à temática.

PALAVRAS-CHAVE: Mulheres; Direito Internacional; Direito Humanitário; Direito Penal Internacional; Estupro.

\section{REFERÊNCIAS}

BRITISH BROADCASTING CORPORATION. Nobel da Paz: um chocante relato de Denis Mukwege, médico que venceu prêmio por luta contra estupros em guerras. Disponível em: https://www.bbc.com/portuguese/internacional-45760996. Acesso em: 30, abr. 2019.

GENEBRA, as Convenções. Convenções de Genebra: texto completo. Disponível em: http://www.gddc.pt/direitos-humanos/textos-internacionais-dh/tidhuniversais/dihconv-IV-1208-1949.html\#tiii_seciii. Acesso em 09. abr. 2019.

GUSTIN, Miracy Barbosa de Sousa; DIAS, Maria Tereza Fonseca. (Re)pensando a pesquisa jurídica: teoria e prática. 3ª . ed. Belo Horizonte: Del Rey, 2010.

HAIA. ICC Trial Chamber III sentences JeanPierre Bemba Gombo to 18 years' i mprisonment for war crimes and crimes against humanity committed in the Ce ntral African Republic in 2002-2003. Disponível em: https://www.icccpi.int/Pages/item.aspx?name=PR1223. Acesso em: 2. mai. 2019.

HASTINGS, Max. Inferno: o mundo em guerra. Rio de Janeiro: Editora Intrínseca, 2012.

INTERNATIONAL CRIMINAL COURT. Central African Republic. Disponível em: https://www.icc-cpi.int/car. Acesso em: 20, abr. 2019.

LEGAL TOOLS. What are ICC Legal Tools?. Disponível em: http://www.legaltools.org/en/what-are-the-icc-legal-tools/. Acesso em: 21, abr, 2019.

MUKWEGE FOUNDATION. Wartime Sexual Violence and the Law. Disponivel em: https://www.mukwegefoundation.org/the-problem/rape-as-a-weapon-of-war/the-law/". Acesso em: 3, abr, 2019. 
Personalidade Acadêmica Homenageada:

Raymundo Juliano Feitosa (Universidade Federal do Rio Grande do Norte - UFRN)

MURAD, Nadia. Eu serei a última. São Paulo: Editora Objetiva, 2018.

NETO, Platon Teixeira de Azevedo. A justiciabilidade dos Direitos Sociais nas Cortes Internacionais de Justiça. São Paulo: Editora LTr.

NAÇÕES UNIDAS. ONU apresenta medidas para reforçar proteção a civis no Congo. Disponível em http://nacoesunidas.org/onu-apresenta-medidas-parareforcar-protecao-a-civis-no-congo/. Acesso em: 2. mai. 2019.

ONU: Comunidade Internacional deve lembrar princípio da responsabilidade de proteger. Disponível em: https://nacoesunidas.org/onucomunidade-internacional-deve-lembrar-principio-da-responsabilidade-de-proteger/. Acesso em: 17, abr, 2019.

PINTO, Catarina A. S. W. A Proteção de Mulheres em Conflitos Armados Não Internacionais. Belo Horizonte: Editora Conhecimento, 2018.

PONTIFÍCIA UNIVERSIDADE CATÓLICA DE MINAS GERAIS. Pró-Reitoria de Graduação. Sistema Integrado de Bibliotecas. Orientações para elaboração de trabalhos científicos: projeto de pesquisa, teses, dissertações, monografias, relatório entre outros trabalhos acadêmicos, conforme a Associação Brasileira de Normas Técnicas (ABNT). 3. ed. Belo Horizonte: PUC Minas, 2019. Disponível em: www.pucminas.br/biblioteca. Acesso em: 10, mai, 2019.

RAMOS, André de Carvalho. Curso de Direitos Humanos. 5a ed. São Paulo: Editora Saraiva Jur.

SILVA, Sandra E. C. Dutra e. Cooperação Internacional para o desenvolvimento sob uma nova perspectiva. Revista Jurídica - UNICURITIBA. V. 1, n. 13 (2011). Disponível em: http://revista.unicuritiba.edu.br/index.php/RIMA/article/view/187/162. Acesso em 26 maio de 2019.

SHAW, Michael N. Direito Internacional. São Paulo: Editora Martins Fontes, 2003.

THE NOBEL PRIZE. The Nobel Peace Prize for 2018. Disponível em: https://www.nobelprize.org/prizes/peace/2018/press-release/. Acesso em: 1. mai. 2019.

TRINDADE, Antônio Augusto Cançado. A Humanização do Direito Internacional. $2^{\mathrm{a}}$ ed. Belo Horizonte: Del Rey editora, 2015.

TRINDADE, Antônio Augusto Cançado. Tratado de Direito Internacional dos Direitos Humanos. $2^{\mathrm{a}}$ ed. Porto Alegre: Sérgio Antônio Fabris Editor, 2003.

UNIVERSIDADE FEDERAL DE MINAS GERAIS. Juiz Cançado Trindade, do Tribunal da Haia, receberá o título de Doutor Honoris Causa. Disponível em: 
Personalidade Acadêmica Homenageada:

Raymundo Juliano Feitosa (Universidade Federal do Rio Grande do Norte - UFRN)

https://ufmg.br/comunicacao/noticias/juiz-antonio-augusto-cancado-trindade-recebetitulo-de-honoris-causa-1. Acesso em: 2. mai. 2019.

VIENA. The Viena Convention on the law of treaties. Disponivel em: https://treaties.un.org/doc/publication/unts/volume\%201155/volume-1155-i-18232english.pdf. Acesso em: 2. mai. 2019

WITKER, Jorge. Como elaborar una tesis en derecho: pautas metodológicas y técnicas para el estudiante o investigador del derecho. Madrid: Civitas, 1985. 